\title{
Institucionalização Partidária e Consistência Programática: A Resposta da Esquerda a Ataques Especulativos na América Latina
}

\section{Daniela Campello}

Escola Brasileira de Administração Pública (Ebape), da Fundação Getulio Vargas (FGV-RJ). Rio de Janeiro, RJ, Brasil. E-mail: daniela.campello@fgv.br

\begin{abstract}
eleição de Lucio Gutiérrez, no Equador, em 2002, ilustra as barA reiras impostas pelo mercado financeiro à adoção de uma agenda de esquerda na América Latina. Gutiérrez, um coronel da reserva que desempenhara um papel importante no golpe que depôs o presidente Jamil Mahuad em 2000, concorreu com um discurso "independente" de esquerda, apoiado por um pequeno partido marxista, grupos radicais indígenas e sindicatos. Durante a campanha presidencial, Gutiérrez criticou a dolarização da economia, prometeu aumentar os gastos do governo e promover a redistribuição de renda. Propôs, ainda, que países da América Latina se unissem com o objetivo de renegociar coletivamente a dívida externa da região.
\end{abstract}

A reação do mercado financeiro à perspectiva da vitória de Gutiérrez foi marcadamente negativa, levando a um aumento do risco soberano e à fuga de capitais, e impondo custos relevantes à já altamente endividada economia do país. Após a posse, todavia, Gutiérrez surpreendeu seus eleitores e aliados ao adotar um programa econômico conservador, radicalmente oposto àquele previamente anunciado. Essa mudança programática permitiu ao presidente rapidamente fechar um acordo com o Fundo Monetário Internacional (FMI), no qual se comprometeu a manter a dolarização da economia, adotar metas de inflação, eliminar subsídios no preço do gás de cozinha, repassar serviços públicos para concessionárias privadas e congelar salários estatais (Hurtado, 2006).

DADOS - Revista de Ciências Sociais, Rio de Janeiro, vol. 58, no-2, 2015, pp. 427 a 460.

http://dx.doi.org/10.1590/00115258201549 
Ainda que a motivação da mudança programática de Gutiérrez tenha sido a necessidade de ganhar a confiança do mercado de forma a atrair capital externo em um período de forte escassez de dólares, características do sistema político equatoriano contribuem para explicar a capacidade do presidente de realizá-la. Um dos sistemas políticos menos institucionalizados da América Latina, o Equador caracteriza-se por fraca identificação ideológica entre eleitores e partidos, baixa disciplina partidária, além de alta fragmentação e volatilidade (Pachano, 2004). Não é incomum que partidos se formem no país com o único propósito de garantir que um candidato independente concorra a eleições; no entanto, tais partidos são parcos em conteúdo programático, fornecendo aos eleitores pouca informação sobre as políticas que possam vir a ser implementadas. Neste cenário, não surpreende que um presidente, empossado no limiar de uma crise financeira, mude imediatamente para um programa político pró-investidor apesar de ter sido eleito com base em promessas de implementação de um conjunto de políticas bem diferentes. Como aponta Tommasi (2003), as crises tendem a pressionar os governos a focarem em horizontes de curtíssimos prazos. Em um sistema pouco institucionalizado, os custos de fazê-lo são relativamente baixos.

A mesma lógica, entretanto, não se aplica a um número de outros exemplos observados na região em que candidatos de esquerda abandonaram suas promessas de campanha em favor de programas neoliberais em sistemas partidários considerados institucionalizados. Esse é o caso de Carlos Andrés Pérez, candidato da Ação Democrática, eleito em 1989 na Venezuela - país apontado como exemplo de institucionalização do sistema partidário até a metade dos anos 1990 - após uma campanha em que prometia um aumento substantivo de salários em todos os setores da economia e uma guerra contra a pobreza, sinalizando a continuação da agenda econômica nacionalista e protecionista do governo de seu antecessor e correligionário Jaime Lusinchi. Empossado, no entanto, Pérez imediatamente voltou atrás com relação ao aumento de salários, eliminou controles de preços e subsídios, e empreendeu um amplo programa de liberalização econômica que garantiu ao país um empréstimo do Fundo Monetário Internacional (Lopez Maya, 2005).

Um processo semelhante ocorreu no Brasil, após uma grave crise de confiança deflagrada no mercado financeiro pelo temor da eleição de Luiz Inácio Lula da Silva, candidato do Partido dos Trabalhadores 
(PT) à Presidência da República em 2002. Mesmo sendo um partido altamente institucionalizado, com raízes na sociedade organizada e consistente do ponto de vista programático, o PT não impediu que Lula da Silva abraçasse um programa substancialmente diferente daquele que historicamente defendera, e muito semelhante àquele ao qual oferecera forte oposição durante os oito anos do governo de Fernando Henrique Cardoso.

À luz dos casos descritos, esse artigo se propõe a testar em que medida a institucionalização de partidos e sistemas partidários logra impedir mudanças programáticas em resposta a repentinas saídas de capital ocorridas durante as eleições presidenciais. A fim de examinar essa questão, codifico o conteúdo programático de campanhas presidenciais e das primeiras iniciativas de governo em eleições ocorridas na América Latina entre os anos de 1982 e 2006. A partir dessa base de dados, analiso empiricamente como diferentes níveis de institucionalização partidária afetam a consistência programática de governos eleitos em meio a ataques especulativos. Os resultados confirmam que, em um cenário de severa saída de capitais, o nível de institucionalização do partido do presidente de fato representa uma barreira a mudanças programáticas. Surpreendentemente, no entanto, a institucionalização do sistema partidário, ao contrário de diminuir, aumenta as chances de que presidentes de esquerda recém-eleitos abandonem promessas de campanha em favor de uma agenda neoliberal.

Este artigo está organizado da seguinte maneira: na primeira seção, analiso a literatura sobre institucionalização partidária e de que forma esta deveria, em princípio, promover a consistência programática de governos. Em seguida, discuto artigos recentes de economistas políticos que tratam da reação do mercado a eleições da esquerda, e formulo hipóteses sobre como essas respostas deveriam influenciar o programa de governos de diferentes matizes ideológicos ${ }^{1}$. A terceira parte apresenta uma análise empírica que testa as hipóteses traçadas em um conjunto de 89 eleições ocorridas na América Latina, cuja conclusão compõe a última seção.

\section{INSTITUCIONALIZAÇÃO PARTIDÁRIA E CONSISTÊNCIA PROGRAMÁTICA}

Desde a publicação da obra seminal de Mainwaring e Scully (1995), muito esforço vem sendo dedicado à determinação dos conceitos envolvidos no processo de institucionalização de sistemas partidários, 


\section{Daniela Campello}

bem como no estabelecimento de suas implicações teóricas para o funcionamento das democracias. A institucionalização é concebida como

um processo através do qual uma prática ou organização se torna bem estabelecida e amplamente conhecida, e atores desenvolvem expectativas, orientações e comportamento com base na premissa de que esta prática ou organização prevalecerá num futuro previsível (Mainwaring e Torcal, 2005:4).

Em sistemas partidários institucionalizados, em que atores políticos desenvolvem expectativas claras e estáveis sobre o comportamento de outros atores. Espera-se, com isso, que padrões estáveis de competição eleitoral, a presença de raízes partidárias na sociedade e o reconhecimento, pelos cidadãos, da legitimidade dos partidos políticos e da institucionalização da organização partidária, em oposição à criação de partidos como veículos eleitorais para líderes personalistas, contribuam para estabelecer o que se considera "boa representação". Esta noção pressupõe representantes que funcionam não como "líderes que buscam realizar sua própria vontade", mas que são eleitos e governam em resposta às preferências programáticas dos eleitores.

A maioria das análises empíricas dedicadas ao estudo da institucionalização de sistemas partidários concentra-se em mensurar níveis de institucionalização. Em comparação, a análise das implicações finais dessa institucionalização tem recebido pouca atenção na literatura. Em particular, a compreensão de como e em que circunstâncias a institucionalização do sistema partidário efetivamente contribui para a consistência programática de atores políticos é incipiente. Este artigo contribui para essa agenda de pesquisa examinando como a institucionalização de partidos e de sistemas partidários, em meio a outras características dos sistemas políticos nacionais, afetam a probabilidade de que governantes de esquerda mantenham sua consistência programática.

Crises econômicas possibilitam oportunidades particularmente interessantes para a análise deste tema. Não raramente a literatura que estuda respostas políticas a essas crises minimiza a importância normativa da consistência programática, com base na ideia de que a assimetria de informações entre eleitores e seus representantes justifica tomadas de decisões que muitas vezes confrontam as preferências do eleitorado. Stokes (2001), por exemplo, argumenta que governantes podem ser considerados ainda melhores representantes de seus eleitores exatamente por renunciarem a suas promessas de campanha em circunstâncias nas quais fazê-lo garantiria os melhores resultados eco- 
nômicos. Para outros autores, as crises encorajam a delegação, não apenas do Legislativo para o Executivo, mas também dos eleitores aos seus representantes (Weyland, 1996; Tommasi, 2003). Contudo, se a delegação nos períodos de crise pode facilitar respostas imediatas dos governantes, nota-se que no longo prazo ela pode impor altos custos econômicos e políticos (Stokes, 2001; Tommasi, 2003; Weyland, 2004; Zechmeister e Luna, 2005). Tommasi afirma: “As crises constituem, talvez, os momentos menos propícios para a construção deliberativa de acordos e consensos necessários para sustentar políticas de qualidade e reformas institucionais sólidas" (2003:16; tradução livre).

Esse tema não interessa apenas aos estudiosos da América Latina. Recentemente, países europeus em sistemas políticos consolidados tais como o da Espanha ou de Portugal, passaram pela experiência de ver governos de esquerda abraçarem uma agenda econômica ortodoxa em resposta a pressões especulativas, mesmo em face de forte oposição interna e da perda de apoio do eleitorado. A fim de informar os debates teóricos e normativos sobre crises e representação, no entanto, é necessário, antes de tudo, determinar empiricamente como os governantes efetivamente se comportam em tempos de crise. Levando-se em consideração a literatura já discutida, a expectativa é de que tanto a institucionalização do partido como a do sistema partidário criem barreiras para que presidentes realizem mudanças programáticas em resposta a crises econômicas. Padrões estáveis de competição eleitoral, a presença de raízes partidárias na sociedade e o reconhecimento pelos cidadãos da legitimidade dos partidos políticos deveriam aumentar os custos eleitorais para presidentes que decidam abertamente abandonar seu programa de governo.

Caso tais motivações não sejam suficientes para impedir mudanças programáticas, espera-se que partidos institucionalizados sejam capazes de vetar a iniciativa de presidentes de adotar políticas opostas àquelas anunciadas durante a campanha. Ao não fazê-lo, os partidos se arriscariam a perder o apoio de ativistas e legisladores, além de eleitores comuns. Em tese, quanto mais institucionalizado o partido, maior deveria ser o custo político imposto ao presidente que decidisse mudar radicalmente de agenda.

\section{ATAQUES ESPECULATIVOS E MUDANÇAS PROGRAMÁTICAS NA AMÉRICA LATINA}

O comportamento do mercado financeiro durante eleições nacionais, bem como suas consequências para o funcionamento de governos 
democráticos, vem adquirindo progressiva relevância na literatura de economia política. Isso se dá na medida em que campanhas eleitorais são o momento crucial em que candidatos revelam seus programas econômicos e investidores reagem em proporção ao impacto esperado destes programas sobre a rentabilidade do investimento. Programas considerados desfavoráveis podem deflagrar desde um aumento do custo de endividamento público até ataques especulativos capazes de impor perdas relevantes para a economia do país. Não é surpreendente, assim, que reações como aquelas observadas durante a eleição de Gutiérrez ou Lula da Silva em 2002 criem barreiras à implementação da agenda de governos contra os quais elas se façam sentir.

Eleições presidenciais na América Latina são particularmente inquietantes para investidores: características dos sistemas políticos locais, tais como a concentração do poder político no Executivo, aumentam consideravelmente a volatilidade de políticas econômicas, gerando incerteza. Altos níveis de personalização, baixa institucionalização dos sistemas partidários e politização da máquina do Estado só reforçam essa incerteza, colocando a agenda dos candidatos presidenciais no centro das atenções de investidores durante o período eleitoral. Relatórios divulgados por analistas durante campanhas presidenciais na América Latina dedicam-se primordialmente a captar as tendências políticas destes candidatos, bem como a natureza e a consistência de seu programa econômico.

Em geral, estes relatórios avaliam positivamente a perspectiva de vitória de governos economicamente conservadores, dos quais se espera que priorizem um bom clima para investimento e promovam políticas favoráveis ao capital privado (Santiso, 2005; Block, Vaaler e Schrage, 2006). Dentre essas políticas, destacam-se a redução da intervenção do Estado na economia, a redução dos impostos e de gastos públicos (Wibbels e Arce, 2003) e a desregulamentação das relações de trabalho, do comércio e de fluxos de capital. Do ponto de vista macroeconômico, investidores tendem a favorecer uma política monetária ortodoxa, orientada primordialmente ao controle da inflação (Oatley, 1999). Por outro lado, investidores frequentemente reagem de forma negativa a governos de esquerda que, ao priorizarem justiça social em relação à eficiência econômica (Bobbio, 1994) e o emprego em relação ao controle da inflação, limitam a rentabilidade do investimento privado. Governos de esquerda tendem a proteger o mercado de trabalho (Botero et al., 2004) e a expandir o setor público no esforço de promover o em- 
prego. Eles também são considerados menos propensos ao conservadorismo fiscal e mais inclinados a distribuir renda (Bobbio, 1994). Em países menos desenvolvidos e altamente endividados, governos de esquerda revelam-se menos comprometidos com o serviço da dívida pública (Mosley, 2003), e mais propensos a impor controles de capital e a nacionalizar empresas privadas.

Por todas essas razões, é plausível imaginar que investidores prefiram aumentar sua exposição em países onde se antecipa que candidatos conservadores venham a ser eleitos presidentes e, ao contrário, que diminuam seus investimentos naqueles nos quais é esperada a vitória de um governo de esquerda. Numerosos estudos de caso confirmam esse comportamento (Yantek e Cowart, 1986; Mauser e Fitzsimmons, 1991; Herron, 2000; Vuchelen, 2003; Santiso e Martínez, 2003). Sabe-se, ainda, que governos com um percentual mais alto de ministros de esquerda pagam taxas de juros mais elevadas do que aqueles em que membros conservadores prevalecem (Mosley, 2003; Garrett, 1998; Leblang e Bernhard, 2000) e que ataques especulativos têm maior probabilidade de ocorrer após a eleição de um governo de esquerda, tanto em países desenvolvidos (Leblang e Bernhard, 2000) quanto naqueles em desenvolvimento (Leblang, 2002). Na América Latina, em particular, Blocke Vaaler (2004) mostram que agências diminuem a classificação de risco da dívida de países que elegem governos de esquerda, enquanto Campello (2015) demonstra que estes governos apresentam risco soberano mais alto do que aqueles de tendência conservadora.

Diante dessas reações pode-se esperar que, em princípio, a eleição da esquerda deflagre algum nível de fuga de capitais. Consistentes com essa expectativa, na amostra analisada neste artigo, ataques especulativos ocorrem com maior frequência quando há a perspectiva de vitória de um candidato de esquerda - $63 \%$ comparados com $37 \%$ no caso de candidatos eleitos com um discurso neoliberal. Resta saber, no entanto, em que circunstâncias esta resposta do mercado torna-se capaz de forçar uma "ida para o centro" de governos de esquerda recémeleitos. A hipótese aqui investigada é a de que em períodos de abundância de dólares, quando a liquidez internacional é alta e os termos de troca são favoráveis, essa resposta não restringe a agenda de governos de esquerda. Ao contrário, é diante da escassez de dólares, quando a liquidez internacional encontra-se baixa e os termos de troca estão francamente desfavoráveis, que a reação do mercado se torna relevante. Confrontados com um cenário de forte pressão cambial, governos de 
esquerda veem-se forçados a renunciar à sua agenda em favor de políticas destinadas a ganhar a confiança do mercado e atrair capital para a economia doméstica.

Neste contexto, autores notam que reformas neoliberais foram frequentemente adotadas na América Latina com o intuito de sinalizar uma agenda pró-mercado (Calvo, Leiderman e Reinhart, 1993; Fernández-Arias e Montiel, 1995). Santiso e Martínez (2003:27) afirmam, explicitamente, que "a febre de reforma na América Latina dos anos 1990 deve ser vista no contexto da necessidade urgente de novos fluxos de capital". A mesma lógica é apontada por Drake (1991:36), que caracteriza as mudanças programáticas frequentemente empreendidas pela esquerda latino-americana como um reflexo da "contradição entre o empobrecimento da maioria da população e os imperativos da reestruturação neoliberal que favorecem mecanismos de mercado e priorizam o pagamento da dívida externa". A coincidência entre os fenômenos descritos por Santiso e Martínez e Drake sugere que a lógica proposta aqui - adoção de uma agenda liberal por parte da esquerda no intuito de atrair capital em tempos de escassez - não se encontra restrita ao período imediatamente posterior à crise da dívida dos anos 1980, ao qual Drake se referia, ou ao princípio dos anos 1990, como tratam Santiso e Martínez. Argumenta-se, neste estudo, que essa lógica se verifica em períodos de escassez de dólares em geral, quando governos estão sujeitos a uma forte pressão para atrair capital externo no curto prazo.

Não é surpreendente, assim, que o tão debatido ressurgimento da esquerda observado na América Latina desde o princípio dos anos 2000 (Castañeda, 2006, 2008; Levitsky e Roberts, 2011; Edwards, 2010; Weyland, Madrid e Hunter, 2010) tenha se dado em uma época em que os termos de troca encontravam-se francamente favoráveis a países exportadores de produtos básicos, e as taxas de juros internacionais atingiam mínimos históricos, atraindo o capital financeiro internacional para países emergentes. Rápido crescimento econômico e ampla oferta de dólares aumentaram a margem de manobra de governos de esquerda para rejeitar as políticas econômicas ortodoxas preferidas pelo mercado (Kaufman, 2011; Murillo, Oliveros e Vaishnav, 2011; Campello, 2015; Weyland, 2009).

Por fim, é importante notar que presidentes eleitos com um discurso neoliberal recebem um mandato para promover o clima de investi- 
mento e liberalizar a economia, e desta forma não experimentam contradição entre as preferências de seus eleitores e do mercado. Na ausência desta contradição, não há porque esperar que a escassez ou abundância de dólares afetem a política econômica prevalecente. É possível que tais governos adotem medidas compensatórias em tempos de abundância, mas eles devem, em tese, fazê-lo dentro dos parâmetros estabelecidos pela ortodoxia macroeconômica.

A argumentação proposta até aqui se sumariza nas seguintes hipóteses. Mantidas as demais condições fixas,

Hipótese 1: Presidentes de esquerda eleitos durante ataques especulativos apresentam maior probabilidade de renunciar a promessas de campanha em favor de uma agenda neoliberal.

Hipótese 2: Ataques especulativos não influenciam as escolhas programáticas de governos eleitos com uma plataforma neoliberal.

Hipótese 3: A probabilidade de mudanças programáticas deve diminuir proporcionalmente ao nível de institucionalização dos sistemas partidários.

Hipótese 4: A probabilidade de mudanças programáticas deve diminuir proporcionalmente ao nível de institucionalização do partido do governo.

Em seguida, apresento uma análise empírica designada a testar as hipóteses elaboradas.

\section{DESENHO DE PESQUISA E ANÁLISE DE DADOS}

Esta seção testa de que forma ataques especulativos ocorridos durante eleições presidenciais afetam a probabilidade de que presidentes de ambos os espectros ideológicos renunciem, uma vez empossados, à agenda econômica anunciada durante a campanha. Em seguida, verifico como características do sistema político, em particular o nível de institucionalização partidária, influenciam essa probabilidade.

A variável dependente, neste modelo, é a mudança programática. As variáveis explicativas capturam ataques especulativos ocorridos durante o período eleitoral e níveis de institucionalização partidária. São também incluídas variáveis de controle consideradas relevantes para explicar a probabilidade de ocorrência de mudanças programáticas.

DADOS - Revista de Ciências Sociais, Rio de Janeiro, vol. 58, n² 2, 2015 


\section{Variável Dependente: “Mudança Programática”}

A fim de examinar a ocorrência de mudanças programáticas, é necessário identificar (1) o conjunto de políticas anunciadas pelos candidatos durante a campanha eleitoral e (2) o programa que eles efetivamente iniciaram após a posse. Ambos foram codificados segundo o critério proposto por Stokes (2001) no que concerne à classificação de campanhas e programas de esquerda (estatistas) e neoliberais (orientados ao mercado).

Foram classificadas como sendo de esquerda campanhas em que o candidato vencedor prometeu aumentar o papel do Estado e a regulação da economia; priorizar o aumento do emprego e do salário sobre o controle da inflação; restringir importações e a movimentação de capitais; implementar políticas industriais, subsídios a produtos e serviços básicos, e limitar o pagamento da dívida externa. A campanha de Rafael Correa durante as eleições presidenciais de 2006 no Equador ilustra um típico discurso de esquerda. O candidato revelou intenções de renegociar a dívida equatoriana segundo o modelo argentino, condenou a dolarização da economia e prometeu fechar a base militar americana em Manta. Correa reafirmou durante a campanha que sua prioridade seria pagar a "dívida social" do país, e não a dívida pública, e anunciou planos de aumentar o papel do Estado na economia.

Foram classificadas como sendo de direita (do ponto de vista econômico) ou "neoliberais", campanhas em que o vencedor prometeu reduzir o papel do Estado na economia mediante privatização e desregulamentação, priorizar choques anti-inflacionários e/ou orientar a política monetária à manutenção de metas de inflação, eliminar subsídios e barreiras à importação e liberalizar a economia de forma mais ampla. A campanha de Alan García, reeleito presidente do Peru em 2006, exemplifica o tom de um discurso neoliberal. O candidato prometeu priorizar a abertura da economia, promover o investimento internacional e a competição externa, privatizar concessões públicas, manter uma política macroeconômica ortodoxa orientada a metas de inflação e firmar acordos de livre-comércio.

As campanhas eleitorais foram classificadas a partir de dados publicados em jornais no ano imediatamente anterior a cada eleição presidencial, e essa análise me permitiu ampliar a base de dados criada por Stokes de 1995 até 2006. Os mesmos critérios foram aplicados à classificação dos programas iniciados no primeiro ano de cada Presidência. 
As informações utilizadas para codificar cada governo foram obtidas a partir de estudos de casos (Conaghan, Malloy e Abugattas, 1990; Cuddington e Asilis, 1990; Wilson, 1994; Espinal, 1995; Mauceri, 1995; Babb, 1996; Hojman, 1996; Roberts, 1996; Lander e Fierro, 1996; Pastor e Wise, 1997; Weiss, 1997; Blake, 1998; Boito Jr. e Randall, 1998; Cameron e North, 1998; Robinson, 2000), da análise de conteúdo de coberturas jornalísticas, assim como de bases de dados de instituições políticas. Considerando meu interesse específico em mudanças póseleitorais, a codificação de artigos foi restrita àqueles publicados no primeiro ano de mandato dos presidentes e disponíveis na base de dados Lexis Nexis².

A variável dependente mudança programática adquire valor $\mathbf{0}$ quando o programa iniciado após a posse é consistente com as promessas de campanha, e valor $\mathbf{1}$, no caso contrário. A limitação das categorias em apenas dois grupos é, sem dúvida, a simplificação de uma realidade em que governos adotam diferentes gradações de programas de esquerda ou de direita. Entretanto, como Stokes (2001:29) sugere, a dificuldade de quantificar esses matizes "desencoraja codificações contínuas em favor da redução das posições ideológicas a uma categoria dicotômica". As categorias adotadas aqui capturam satisfatoriamente a mensagem básica de campanhas presidenciais, em geral orientadas a um discurso estatista/intervencionista ou pró-mercado/liberalizante.

\section{Variáveis Explicativas}

Ataque especulativo. A variável concebida para captar ataques especulativos foi construída com base no índice de pressão cambial (PC) Exchange Market Pressure - criado por Eichengreen et al. (1995), baseados no trabalho de Girton e Roper (1977). O índice agrega alterações nas reservas internacionais e no câmbio, ponderadas por sua volatilidade histórica, que, por sua vez, é medida pelo desvio-padrão de suas distribuições. A interpretação da PC é simples: pressões especulativas refletem-se tanto na queda de reservas (r), utilizadas pelo governo para manter o valor da moeda, quanto na depreciação da taxa de câmbio (c), caso o governo opte por deixá-la flutuar:

$$
\mathrm{EMP}_{\mathrm{i}, \mathrm{t}}=\Delta \mathrm{c}_{\mathrm{i}, \mathrm{t}} / \sigma \Delta \mathrm{c}_{\mathrm{i}, \mathrm{t}}-\Delta \mathrm{r}_{\mathrm{i}, \mathrm{t}} / \sigma \Delta \mathrm{r}_{\mathrm{i}, \mathrm{t}}
$$

Eichengreen et al. (1995) utilizam um mesmo desvio-padrão para toda a amostra; Leblang (2002), por sua vez, adota um desvio-padrão para cada país. Alternativamente, calculo aqui uma média móvel (12 me- 
ses) dos desvios-padrão. Esta medida é mais adequada à realidade da América Latina, uma vez que ambos os indicadores que compõem o índice mostram-se altamente voláteis nos primeiros anos da amostra, ao passo que a volatilidade decresce significativamente ao longo do período estudado. $\mathrm{O}$ uso de um desvio-padrão único, portanto, superestimaria as crises ocorridas no início dos anos 1980 e, ao mesmo tempo, subestimaria aquelas observadas no final dos anos 1990.

De acordo com Eichengreen et al. (1995), criei em seguida uma variável binária com a finalidade de capturar a ocorrência de uma crise cambial (CC). Sempre que a pressão cambial assume valores negativos extremos em um determinado mês - consistente com Leblang (2002), adotei um corte de dois desvios-padrão ao redor da média da distribuição.

$$
\mathrm{CC}_{\mathrm{i}, \mathrm{t}}=\left\{\begin{array}{l}
1, \operatorname{sePC}_{\mathrm{i}, \mathrm{t}}>\mu\left(\mathrm{PC}_{\mathrm{i}, \mathrm{t}}\right)+2 \sigma\left(\mathrm{PC}_{\mathrm{i}, \mathrm{t}}\right) \\
0, \text { caso contrário }
\end{array}\right.
$$

Neste modelo, a variável ataque especulativo resulta da soma dos valores de crise cambial nos 13 meses centrados na posse de um presidente. Ela captura ataques especulativos - saídas súbitas e significativas de capital - ocorridos no período que vai, em média, de seis meses antes da eleição até os primeiros seis meses do mandato presidencial.

Como discutido na seção teórica, é possível que presidentes tentem mudar seus programas quando se defrontam com ataques especulativos, mas é mais provável que o façam em sistemas políticos menos estruturados. As variáveis utilizadas para capturar os níveis de institucionalização do sistema partidário e de partidos políticos são descritas a seguir.

Volatilidade. A volatilidade eleitoral é a variável mais facilmente mensurável e, talvez, a mais importante dimensão da institucionalização do sistema partidário, uma vez que a "institucionalização está conceitualmente muito próxima da estabilidade" (Mainwaring e Torcal, 2005:4). Enquanto a institucionalização do sistema partidário compreende pelo menos três outras dimensões além da estabilidade da competição intrapartidária, captada pela volatilidade, este ainda é o fator mais utilizado em trabalhos empíricos que procuram quantificar a noção de institucionalização. Para a amostra estudada neste artigo, a volatilidade em eleições para o Congresso é calculada utilizando dados obtidos a partir da Base de Dados Políticos das Américas - Political 
Database of the Americas (PDBA) - e do arquivo eleitoral de Adam Carr ${ }^{3}$.

Idade do Partido. Esta variável é usada aqui como um indicador da institucionalização do partido do presidente. Não obstante o fato de alguns partidos existirem por muito tempo sem alcançar um alto nível de institucionalização, como é o caso do Partido Justicialista na Argentina, por exemplo, entende-se que tempo de existência é uma condição necessária para a institucionalização e, portanto, fortemente associado com ela. Dados foram obtidos da Base de Dados de Instituições Políticas - Database of Political Institutions (DBPI) - e também de dicionários políticos da América Latina (Gunson, Chamberlain e Thompson, 1989, 1991; Ameringer, 1992).

\section{Variáveis de Controle}

Além de níveis de institucionalização, outras características de sistemas políticos também podem influenciar a probabilidade de que presidentes efetuem mudanças programáticas, e por isso são incluídas como controle na análise apresentada a seguir. Entre elas, estão os poderes constitucionais atribuídos ao Executivo e a força do partido do governo na legislatura.

Em tese, quanto maior o poder concentrado no Executivo, mais fácil será para o presidente realizar uma mudança programática que confronte as preferências de outros atores políticos. Adicionalmente, uma vez que o presidente encontre apoio no seu próprio partido para realizar mudança de programas, o Congresso ainda pode impor um veto a tal mudança. Entretanto, a probabilidade de esse veto acontecer é menor quanto mais forte for a presença do partido da situação ${ }^{4}$. Com isso, espera-se que a concentração de poderes no Executivo e o poder de seu partido no Congresso aumentem a capacidade do presidente de realizar uma mudança programática, caso decida fazê-lo. Para capturar esses fatores são utilizadas as seguintes variáveis:

Executivo. Esta variável reflete os poderes constitucionais do Executivo e seus valores foram obtidos do Inter-American Development Bank/Institute for Democracy and Electoral Assistance (IDB/IDEA) (Payne et al., 2002). O índice cobre uma escala que vai de 3 a 15, incluindo medidas de veto total, veto parcial, poder de decreto, iniciativa exclusiva, convocação de referendo/plebiscito, poder de definir e de descumprir o orçamento. 
Legislatura. O número de cadeiras controladas pelo partido da situação na Câmara dos Deputados foi utilizado como indicador da força do governo no Legislativo. As fontes de consulta foram, também, o IDB/IDEA, a PDBA e o arquivo de Adam Carr 5 .

Inflação. Finalmente, como a necessidade de lidar com as crises inflacionárias constitui uma explicação amplamente aceita para a adoção de programas neoliberais na América Latina (Weyland, 1996; Stokes, 2001; Biglaiser, 2004; Bresser-Pereira, 2006), em tese, a hiperinflação não apenas motiva presidentes a adotar ajustes dolorosos (Haggard e Kaufman, 1995; Stokes, 2001), mas também torna o cidadão mais afeito a riscos ao colocá-lo no "domínio das perdas" (Weyland, 1996). Com o intuito de separar os efeitos de crises cambiais e crises inflacionárias, foi incluída a variável Inflação, que mede o logaritmo da taxa média anual de inflação nos 13 meses centrados na data da posse dos presidentes. Estatísticas descritivas são apresentadas na Tabela 1.

Tabela 1

Resumo das Variáveis Explicativas Incluídas na Análise

\begin{tabular}{l|c|c|c|c|c}
\hline Variável & Mínima & Mediana & Média & Máxima & Desvio-padrão \\
\hline Ataque especulativo & 0,00 & 4,00 & 4,29 & 13,00 & 3,61 \\
Volatilidade & 3,30 & 18,70 & 22,67 & 62,80 & 14,04 \\
Idade do partido & 1,00 & 24,00 & 42,35 & 165,00 & 46,69 \\
Executivo & 3,00 & 7,00 & 7,97 & 15,00 & 3,68 \\
Legislatura & 0,00 & 41,40 & 36,05 & 96,00 & 19,06 \\
Inflação & $-0,19$ & 2,49 & 2,85 & 9,26 & 1,73 \\
\hline
\end{tabular}

Fonte: Dados calculados pela autora com base nas fontes descritas na seção “Desenho de Pesquisa e Análise de Dados" deste artigo.

\section{Resultados}

Como ataques especulativos afetam a consistência programática de governos na América Latina? Levando-se em conta que - como se espera - o efeito desses ataques seja diferente dependendo do matiz ideológico do candidato/presidente, os casos de candidatos neoliberais e de esquerda são analisados separadamente. Essa estratégia tem a vantagem adicional de evitar potencial endogeneidade nos resultados, causada pelo fato de que um componente da variável dependente (o conteúdo programático da campanha presidencial) pode influenciar os valores da variável independente (ataque especulativo). 


\section{Campanhas Neoliberais}

O impacto nulo de ataques especulativos em mudanças programáticas realizadas por presidentes neoliberais é evidente uma vez que se observa que, apesar de o tratamento variar (o valor mediano da variável ataque especulativo, nesses casos, é de 3,73, com desvio-padrão de 3,70), os efeitos permanecem constantes (candidatos eleitos após uma campanha neoliberal jamais realizam mudanças programáticas). Caso nem o tratamento nem o efeito variassem, seria impossível determinar a influência de ataques especulativos sobre governos neoliberais. Da forma como os dados se apresentam, a evidência é consistente com a hipótese de que ataques especulativos não têm um impacto sobre as escolhas programáticas deste grupo (Hipótese 2).

\section{Campanhas de Esquerda}

Os resultados da análise indicam que, dentre os presidentes de esquer$\mathrm{da}$, aqueles que iniciam seu governo em meio a um ataque especulativo são os que mais provavelmente trairão as promessas de campanha em favor de um programa econômico neoliberal.

A Tabela 2 mostra o efeito das mudanças nas principais variáveis explicativas (primeiras diferenças, no modelo probit) sobre a probabilidade de que presidentes adotem um programa distinto daquele anunciado durante a campanha. Os resultados são consistentes com a hipótese de que ataques especulativos - saídas súbitas e significativas de dólares da economia - aumentam significativamente a chance de que presidentes esquerdistas adotem um programa neoliberal já no início de seu mandato (Hipótese 1).

Mantendo todas as outras variáveis em seus valores médios, uma mudança de dois desvios-padrão em torno da média da variável ataque especulativo leva a uma variação de 54,5 pontos percentuais na probabilidade de um presidente de centro-esquerda mudar seu programa (Modelo 4). Esse efeito é estatisticamente significativo em um intervalo de confiança de 95\% (Figura 1a). De acordo com o modelo, por exemplo, se Lucio Gutiérrez houvesse assumido o governo equatoriano em 2002 (ataque especulativo $=10$ ) nas mesmas condições em que Rafael Correa em 2006 (ataque especulativo = 3), a probabilidade de que ele tivesse renunciado à sua agenda de esquerda em favor de políticas neoliberais teria sido 48 pontos percentuais inferior. 
Tabela 2

Efeitos das Variáveis Explicativas sobre a Probabilidade de que Presidentes de Esquerda Realizem uma Mudança Programática.

Primeiras Diferenças, Modelo probit

Variável Dependente: Mudança Programática

\begin{tabular}{|c|c|c|c|c|}
\hline & Modelo 1 & Modelo 2 & Modelo 3 & Modelo 4 \\
\hline Ataque especulativo & 0,489 & & 0,546 & 0,545 \\
\hline Erro-padrão & $(0,164)$ & & $(0,217)$ & $(0,208)$ \\
\hline prob. & 0,003 & & 0,012 & 0,009 \\
\hline Volatilidade & & $-0,737$ & $-0,790$ & $-0,812$ \\
\hline Erro-padrão & & $(0,189)$ & $(0,200)$ & $(0,183)$ \\
\hline prob. & & 0,000 & 0,000 & 0,000 \\
\hline Idade do partido & & $-0,708$ & -0.747 & $-0,749$ \\
\hline Erro-padrão & & $(0,209)$ & $(0.220)$ & $(0,230)$ \\
\hline prob. & & 0,001 & 0,001 & 0,001 \\
\hline Executivo & & 0,425 & 0,598 & 0,595 \\
\hline Erro-padrão & & $(0,261)$ & $(0,251)$ & $(0,264)$ \\
\hline prob. & & 0,104 & 0.017 & 0,024 \\
\hline Legislatura & & 0,208 & 0,314 & 0,272 \\
\hline Erro-padrão & & $(0,261)$ & $(0,285)$ & $(0,290)$ \\
\hline prob. & & 0,425 & 0,270 & 0,360 \\
\hline Inflação & & & & 0,191 \\
\hline Erro-padrão & & & & $(0,259)$ \\
\hline prob. & & & & 0,459 \\
\hline
\end{tabular}

Fonte: Dados calculados pela autora com base nas fontes descritas na seção “Desenho de Pesquisa e Análise de Dados" deste artigo.

Nota: Efeito de alterações nas variáveis de interesse sobre a probabilidade de que governos de esquerda realizem mudanças programáticas. Parâmetros da simulação: variação de dois desviospadrão em torno da média para a variável de interesse, mantidas todas as outras variáveis em seus valores médios.

O efeito da idade do partido, indicador utilizado como proxy para o nível de institucionalização do partido do presidente, mostrou-se consistente com as expectativas (Hipótese 4 ) e estatisticamente significativo ( $\mathrm{Fi}$ gura 1d), sugerindo que a institucionalização partidária de fato constitua uma barreira para mudanças programáticas. Quanto ao efeito da institucionalização de sistemas partidários sobre a probabilidade de que governos de esquerda governem com uma agenda neoliberal, os resultados sugerem um efeito oposto ao esperado (Figura 1c). O sinal da variável volatilidade mostrou-se negativo e significativo, e consistente em todos os modelos observados, contrariando a hipótese de que 


\section{Figura 1}

Efeitos das Variáveis Explicativas na Probabilidade de que Ocorra uma Mudança Programática. Modelo probit. Variável Dependente: Mudança Programática

1a) Ataque Especulativo

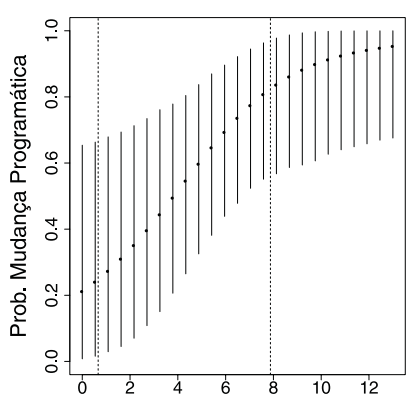

1c) Volatilidade

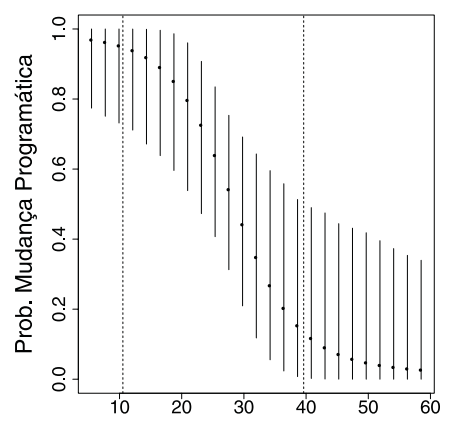

1e) Executivo

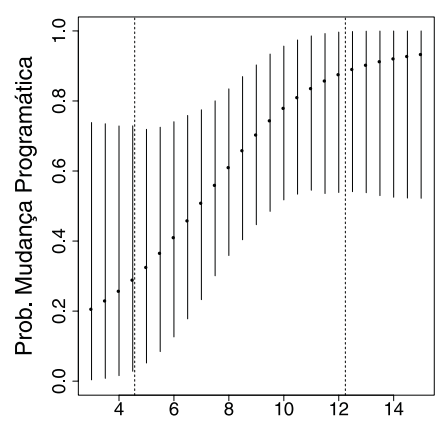

1b) Inflação

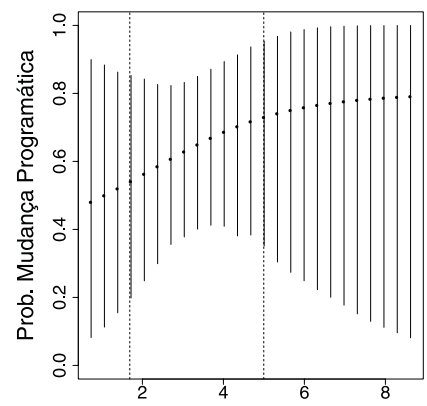

1d) Partido

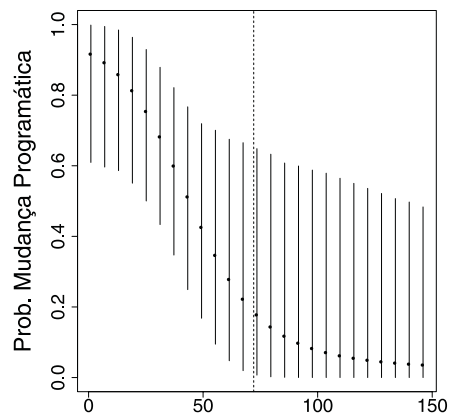

1f) Legislatura

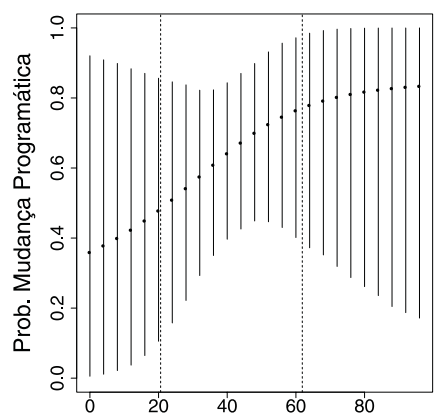

Fonte: Dados calculados pela autora com base nas fontes descritas na seção "Desenho de Pesquisa e Análise de Dados" deste artigo.

Nota: Efeitos das variáveis explicativas sobre a probabilidade de que presidentes de esquerda realizem uma mudança programática. Simulação Zelig-R (Imai, King e Lau, 2008), rodadas = 50, as linhas pontilhadas representam um intervalo de confiança de $95 \%$. As linhas verticais denotam um intervalo de dois desvios-padrão ao redor do valor médio da variável explicativa. 
mudanças programáticas são menos prováveis em sistemas partidários mais institucionalizados (Hipótese 3).

Uma possível explicação seria a de que a volatilidade eleitoral estivesse capturando os efeitos possivelmente negativos da fragmentação do sistema partidário em mudanças programáticas. Mantidas as outras condições, quanto mais fragmentado for o Legislativo, mais difícil será para o presidente obter apoio da maioria e implementar sua agenda programática. No entanto, a baixa correlação entre estas duas variáveis $(0,14)$ e o fato de que a inclusão da fragmentação do sistema partidário no modelo não produziu qualquer alteração que impactasse a probabilidade de mudanças, e tampouco qualquer resultado sobre o efeito das demais variáveis explicativas, sugere que esse não é o caso. Outra alternativa para um impacto potencialmente negativo da volatilidade sobre as chances de presidentes promoverem mudanças programáticas pode derivar do fato de que os eleitores, deparados com resultados econômicos ruins, tendem a punir mais severamente os governantes que mudaram seus programas comparativamente àqueles que não efetuaram mudanças (Stokes, 2001). Pode-se argumentar que os políticos só se atrevem a trair abertamente as promessas de campanha quando sabem que podem contar com a fidelidade dos eleitores ${ }^{6}$.

Finalmente, é importante notar que a volatilidade eleitoral é um melhor indicador da institucionalização de sistemas partidários tão mais a estabilidade da competição eleitoral esteja associada com a existência de raízes partidárias programáticas estáveis na sociedade. Na ausência de vínculos programáticos estáveis entre partidos e eleitores, como Luna (2008) argumenta ser o caso da América Latina, parece plausível que a estabilidade da competição eleitoral não seja capaz de garantir a consistência programática dos governos. Este raciocínio é coerente com a observação de Zucco Jr. (2008) de que a estabilidade nos padrões de competição eleitoral, por si só, produziu uma série de benefícios políticos nas democracias latino-americanas, mas que a capacidade dos eleitores de determinar a agenda programática dos governos não está entre eles. A incapacidade de eleitores de influenciar a agenda pública na América Latina vem sendo apontada por outros autores como uma das razões da baixa qualidade da democracia em consolidação na região (Weyland, 2004).

Entre as demais variáveis, o efeito de poderes constitucionais do Executivo é positivo e consistente (Figura 1e), compatível com a expectati- 
va de que quanto maiores os poderes constitucionais que o sistema político atribui ao Executivo, maior será a probabilidade de uma mudança programática. Um aumento de dois desvios-padrão na variável executivo aumenta em cerca de 60 pontos percentuais as chances de um presidente de esquerda mudar para um programa neoliberal significativo a um nível de 5\%. Interessantemente, a concentração de poderes no Executivo só apresenta efeito sobre a probabilidade de mudança programática na presença de ataques especulativos (Figuras 2a e 2b). $\mathrm{O}$ fato de que os executivos fortes - e não os fracos - são aqueles que mais provavelmente realizarão uma mudança programática na presença de um ataque especulativo reforça a tese de que essas mudanças não são motivadas pela necessidade de negociar com o Congresso para garantir a governabilidade e, sim, pela urgência de ganhar a confiança do mercado e atrair dólares para a economia em tempos de escassez.

Em comparação, o sinal da variável legislatura, que reflete a força do partido da situação no Congresso, mostrou-se consistentemente positivo, como se esperava, mas nunca significativo (Figura 1f). Esse resultado é consistente com o fato de que, nos presidencialismos típicos dos

Figura 2

Efeitos da Variável Executivo na Probabilidade de que Governos de Esquerda Realizem uma Mudança Programática, com e sem a Presença de um Ataque Especulativo. Modelo probit. Variável Dependente: Mudança Programática

2a) Com Ataque Especulativo

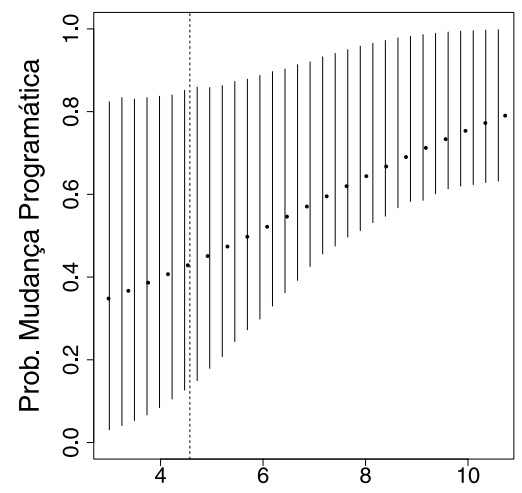

2b) Sem Ataque Especulativo

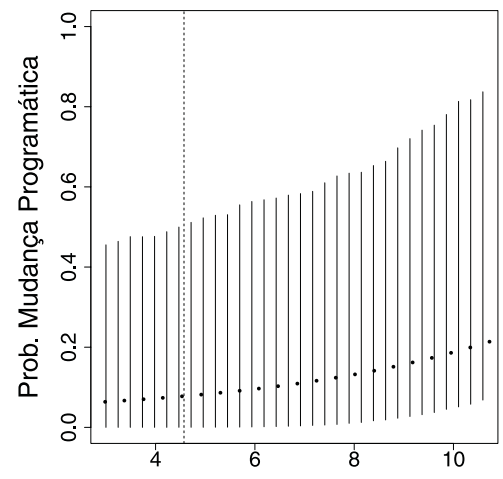

Fonte: Dados calculados pela autora com base nas fontes descritas na seção "Desenho de Pesquisa e Análise de Dados" deste artigo.

Nota: Efeitos das variáveis explicativas sobre a probabilidade de que presidentes de esquerda realizem uma mudança programática, na presença e ausência de ataque especulativo (um desvio-padrão acima e abaixo da média da variável Ataque Especulativo). Simulação Zelig-R (Imai, King e Lau, 2008), rodadas $=50$, as linhas pontilhadas representam um intervalo de confiança de $95 \%$. As linhas verticais denotam um intervalo de dois desvios-padrão ao redor do valor médio da variável explicativa. 
sistemas políticos da região, o partido do presidente raramente possui uma fatia significativa do Congresso e frequentemente precisa formar uma coalizão para governar. Por fim, a inflação, quando controlada pela ocorrência de ataques especulativos, não tem qualquer efeito sobre a probabilidade de mudança programática (Figura 1b).

\section{CONCLUSÃO}

Este artigo investigou se e sob quais condições ataques especulativos ocorridos durante as eleições presidenciais, no período de 1982 a 2006, afetaram a consistência programática de presidentes latino-americanos, e em que medida essa consistência está relacionada aos níveis de institucionalização de partidos e sistemas partidários na região.

A hipótese inicialmente examinada foi a de que as pressões especulativas aumentam as chances de que presidentes eleitos segundo uma plataforma de esquerda, uma vez empossados, adotem programas neoliberais. Segundo a mesma lógica, conjecturou-se que essas pressões não deveriam afetar o comportamento de presidentes eleitos com um discurso neoliberal, já que nesses casos não existem contradições fundamentais entre as preferências de seus eleitores e do mercado. Em seguida, verifiquei se e como fatores políticos, em particular o nível de institucionalização dos partidos e os sistemas partidários, afetam a resposta dos governos aos ataques especulativos.

Os resultados sugerem que, dentre os governos de esquerda eleitos na América Latina, aqueles que iniciaram seus mandatos sob fortes pressões especulativas, e em sistemas nos quais o Executivo detém muitos poderes constitucionais, são os mais propensos a abraçar um programa neoliberal logo após a posse. Isso sugere que os ataques especulativos proveem a motivação, enquanto a concentração de poderes garante a capacidade de presidentes realizarem mudanças programáticas. $\mathrm{O}$ fato de os executivos fortes - e não os fracos - serem os que mais frequentemente mudam de programa é incompatível com a hipótese de que negociações no Congresso ou concessões à oposição sejam as principais motivações dessas mudanças.

Embora partidos menos institucionalizados ofereçam menores barreiras à realização de mudanças programáticas, verificou-se que sistemas partidários institucionalizados mostram-se incapazes de impedir que presidentes de esquerda mudem radicalmente de agenda econômica. Ao contrário, mudanças programáticas ocorrem com maior probabili- 
dade quanto maior for a institucionalização, o que contradiz as alegações de que esta promova a consistência programática. Considerando as limitações intrínsecas aos indicadores utilizados, e que a volatilidade eleitoral mede apenas um dos aspectos da institucionalização dos sistemas partidários, argumentou-se que em sistemas partidários consolidados, nos quais a conexão com eleitores não se dê em bases programáticas, a estabilidade da concorrência partidária pode ocorrer sem necessariamente contribuir para o fortalecimento da consistência do programa de governo. Esta conclusão informa a literatura que trata dos efeitos políticos da institucionalização partidária e aponta para uma interessante agenda de pesquisa voltada para o estudo de como diferentes formas de vinculação entre eleitores e partidos afetam a qualidade da democracia na América Latina.

Além disso, a análise empírica desenvolvida neste artigo contribui para uma agenda ainda recente sobre a influência de investidores em decisões de política econômica de governos democráticos. Os resultados apresentados sugerem que, sob condições econômicas e políticas específicas, investidores têm considerável capacidade para influenciar as escolhas políticas dos governos. A concorrência eleitoral institucionalizada, nestas circunstâncias, não parece suficiente para forçá-los a implementar os programas anunciados em campanha, e com base nos quais foram eleitos.

É importante notar que ataques especulativos constituem uma regularidade em eleições latino-americanas, sobretudo naquelas em que há expectativas de vitória da esquerda. Ao mesmo tempo, mostrou-se que candidatos de esquerda têm uma elevada probabilidade de trair as promessas de campanha e mudar para programas neoliberais quando eleitos em meio a pressões especulativas graves. Diante dessa evidência, esta análise contribui para explicar a persistência de políticas neoliberais na América Latina, apesar do frustrante registro em termos de crescimento econômico e redução da desigualdade de renda sob esses programas. O estudo chama a atenção para um mecanismo - crises de confiança limitando a implementação de programas de esquerda - por meio do qual a liberalização financeira, ocorrida na região desde os anos 1980, contribui para a consolidação de sistemas democráticos em que alternância de poder não conduz necessariamente à alternância de agendas econômicas.

Por outro lado, é importante notar que pressões especulativas tornaram-se menos comuns durante eleições presidenciais ocorridas na 
América Latina a partir de 2003. Neste período, uma subida sem precedentes dos preços das commodities e baixas taxas de juros internacionais propiciaram um abundante fluxo de dólares para a região, aumentando de forma substancial a margem de manobra de governos de esquerda. Mais recursos fiscais e menor necessidade (e maior facilidade) de atrair capital financeiro internacional permitiram a esses governos aumentar gastos sociais e adotar políticas redistributivas e intervencionistas que possivelmente tivessem gerado reações adversas em períodos menos favoráveis.

É preciso notar, no entanto, que uma forte queda nos preços das commodities desde seu auge, em fevereiro de 2011, e a perspectiva de aumento das taxas de juros internacionais na esteira da recuperação da economia americana pós-crise de 2008 sugerem que um novo período de escassez de dólares se aproxima. Se a lógica proposta neste artigo estiver correta, este cenário seria bastante desfavorável para a esquerda latino-americana, uma vez que depois de uma década de bonança, esta voltaria a precisar optar entre a confiança do mercado - com um retorno à ortodoxia e uma retração da presença do Estado na economia - e as preferências de seus eleitores, que mostraram recompensar generosamente as iniciativas redistributivas da década anterior.

(Recebido para publicação em novembro de 2013)

(Aprovado para publicação em outubro de 2014) 


\section{Institucionalização Partidária e Consistência Programática...}

\section{NOTAS}

1. É importante salientar que meu foco se restringe ao programa e a políticas de cunho econômico.

2. Um resumo das classificações de campanha e governo encontra-se no Quadro 1 (Apêndice). A classificação detalhada dos critérios utilizados em cada eleição está disponível mediante requisição à autora.

3. Disponível em http://psephos.adam-carr.net. Acesso em 1/7/2013.

4. Isso ocorre mesmo se o Legislativo tender a favorecer o novo programa. Por exemplo, uma das primeiras iniciativas de Lula da Silva, depois de empossado, foi o lançamento de uma reforma do sistema previdenciário de aposentadorias, há muito tempo exigida pelos investidores e economistas conservadores, mas que não fora aprovada nos governos anteriores devido a uma feroz oposição da esquerda no Congresso, na época liderada pelo próprio PT. Apesar de a maioria da nova legislatura ter apoiado essa reforma, o presidente passou por um longo processo de negociação, a fim de, finalmente, ser capaz de aprovar a nova lei. Zucco Jr. (2008) sugere que os sistemas políticos em que o presidente controla a distribuição de recursos não políticos - o que é comum na América Latina - são suscetíveis de criar uma clivagem entre o governo e a oposição, que independe de preferências ideológicas. Isso implica que a oposição nesses sistemas funcione como um ponto de veto, mesmo quando os presidentes tentam seguir as políticas que os partidos de oposição tradicionalmente apoiam.

5. Foram utilizados apenas dados relativos aos partidos dos presidentes - não envolvendo todos os partidos da base do governo - em razão da dificuldade de definir corretamente essas coalizões na América Latina.

6. Essa lógica é análoga ao fenômeno "Nixon vai à China”, segundo o qual apenas um presidente americano comprovadamente conservador poderia realizar uma aproximação com a China sem despertar suspeitas de estar traindo os valores do Partido Republicano. 


\section{Daniela Campello}

\section{REFERÊNCIAS BIBLIOGRÁFICAS}

AMERINGER, Charles D. (1992), Political Parties of the Americas, 1980s to 1990s. Westport, Greenwood Press.

BABB, Florence E. (1996), “After the Revolution: Neoliberal Policy and Gender in Nicaragua". Latin American Perspectives, vol. 23, no 1, pp. 27-48.

BIGLAISER, Glen. (2004), “The Expansion of Neoliberal Economic Reforms in Latin America". International Studies Quarterly, no 48, pp. 561-578.

BLAKE, Charles H. (1998), “Economic Reform and Democratization in Argentina and Uruguay: The Tortoise and the Hare Revisited?". Journal of Interamerican Studies and World Affairs, vol. 40, no 3, pp. 1-26.

BLOCK, Steven A. e VAALER, Paul M. (2004), “The Price of Democracy: Sovereign Risk Ratings, Bond Spreads and Political Business Cycles in Developing Countries". Journal of International Money and Finance, vol. 23, no 3, pp. 917-946.

BLOCK, Steven A., VAALER, Paul M. e SCHRAGE, Burkhard N. (2006), "Elections, Opportunism, Partisanship and Sovereign Ratings in Developing Countries". Review of Development Economics, vol. 10, no 1, pp. 154-170.

BOBBIO, Norberto. (1994), Left and Right: The Significance of a Political Distinction. Cambridge, Polity Press.

BOITO JR., Armando e RANDALL, Laura. (1998), “Neoliberal Hegemony and Unionism in Brazil". Latin American Perspectives, vol. 25, no 1, pp. 71-93.

BOTERO, Juan et al. (2004), "The Regulation of Labor". The Quarterly Journal of Economics, vol. 11, no 1, pp. 51-81.

BRESSER-PEREIRA, Luiz Carlos. (2006), “O Paradoxo da Esquerda na América Latina”. Novos Estudos Cebrap, no 74, pp. 25-46.

CALVO, Guillermo A., LEIDERMAN, Leonardo e REINHART, Carmen. (1993), “Capital Inflows and Real Exchange Rate Appreciation in Latin America: The Role of External Factors". IMF Staff Papers, vol. 40, no 1, pp. 108-151.

CAMERON, Maxwell A. e NORTH, Lisa L. (1998), "Development Paths at a Crossroads: Peru in Light of the East Asian Experience". Latin American Perspectives, vol. 25, no 1, pp. 50-66.

CAMPELLO, Daniela. (2015), The Politics of Market Discipline in Latin America: Globalization and Democracy. Cambridge, Cambridge University Press.

CASTAÑEDA, Jorge G. (2006), “Latin America's Left Turn”. Foreign Affairs, vol. 24, no 3, pp. 363-395.

( 2008), Left Overs: Tales of the Latin American Left. New York, Routledge.

CONAGHAN, Catherine M., MALLOY, James M. e ABUGATTAS, Luis A. (1990), “Business and the 'Boys': The Politics of Neoliberalism in the Central Andes". Latin American Research Review, vol. 25, no 2, pp. 3-30.

CUDDINGTON, John T. e ASILIS, Carlos. (1990), “Fiscal Policy, the Current Account and the External Debt Problem in the Dominican Republic". Journal of Latin American Studies, vol. 22, no 2, pp. 331-352. 
DRAKE, Paul. (1991), "Comment: The Political Economy of Latin American Populism”, in R. Dornbusch e S. Edwards (eds.), The Macroeconomics of Populism in Latin America. Chicago, The University of Chicago Press, pp. 35-40.

EDWARDS, Sebastian. (2010), Left Behind. Chicago, University of Chicago Press.

EICHENGREEN, Barry et al. (1995), "Exchange Market Mayhem: The Antecedents and Aftermath of Speculative Attacks". Economic Policy, vol. 10, no 21, pp. 249-312.

ESPINAL, Rosario. (1995), "Economic Restructuring, Social Protests and Democratization in the Dominican Republic". Latin American Perspectives, vol. 22, no3, pp. 63-79.

FERNÁNDEZ-ARIAS, Eduardo e MONTIEL, Peter J. (1995), “The Surge in Capital Inflows to Developing Countries: Analytical Overview". World Bank Economic Review, vol. 10, no 1, pp. 51-77.

GARRETT, Geoffrey. (1998), “Global Markets and National Politics: Collision Course or Virtuous Circle?". International Organization, vol. 52, no 4, pp. 787-824.

GIRTON, Lance e ROPER, Don. (1977), "A Monetary Model of Exchange Market Pressure Applied to Postwar Canadian Experience". American Economic Review, vol. 67, no 4, pp. 537-548.

GUNSON, Phil, CHAMBERLAIN, Greg e THOMPSON, Andrew. (1989), The Dictionary of Contemporary Politics of South America. London, Routledge.

(1991), The Dictionary of Contemporary Politics of Central America and the Caribbean. London, Routledge.

HAGGARD, Stephen e KAUFMAN, Robert. (1995), The Political Economy of Democratic Transitions. Princeton, Princeton University Press.

HERRON, Michael. (2000), "Estimating the Economic Impact of Political Party Competition in the 1992 British Election". American Journal of Political Science, vol. 44, no 2, pp. 326-337.

HOJMAN, David E. (1996), "Poverty and Inequality in Chile: Are Democratic Politics and Neoliberal Economics Good for You?". Journal of Interamerican Studies and World Affairs, vol. 78, n으 2-3, pp. 73-96.

HURTADO, Osvaldo. (2006), Los Costos del Populismo. Quito, Cordes.

IMAI, Kosuke, KING, Gary e LAU, Olivia. (2008), “Toward a Common Framework for Statistical Analysis and Development". Journal of Computational and Graphical Statistics, vol. 17, no 4, pp. 892-913.

KAUFMAN, Robert. (2011), "The Political Left, the Export Boom, and the Populist Temptation", in S. Levitsky e K. M. Roberts (eds.), The Resurgence of the Latin American Left. Baltimore, Johns Hopkins University Press, pp. 93-116.

LANDER, Edgardo e FIERRO, Luis A. (1996), "The Impact of Neoliberal Adjustment in Venezuela, 1989-1993". Latin American Perspectives, vol. 23, no 3, pp. 50-73.

LEBLANG, David A. (2002), "The Political Economy of Speculative Attacks in the Developing World". International Organization, vol. 54, no 2, pp. 291-324.

e BERNHARD, William. (2000), "The Politics of Speculative Attacks in Industrial Democracies". International Studies Quarterly, vol. 46, no 1, pp. 69-91.

DADOS - Revista de Ciências Sociais, Rio de Janeiro, vol. 58, nํ 2, 2015 


\section{Daniela Campello}

LEVITSKY, Steven e ROBERTS, Kenneth. (2011), The Resurgence of the Latin American Left. Baltimore, Johns Hopkins University Press.

LOPEZ MAYA, Margarita. (2005), Del Viernes Negro al Referendo Revocatorio. Caracas, Editorial Melvin.

LUNA, Juan Pablo. (2008), Estructura Programática e Institucionalización del Sistema de Partidos. Trabalho apresentado na conferência Institucionalización de los Sistemas de Partidos en América Latina, CIDOB, Barcelona, 20-21 de novembro.

MAINWARING, Scott e SCULLY, Timothy. (1995), Building Democratic Institutions: Party Systems in Latin America. Stanford, Stanford University Press.

MAINWARING, Scott e TORCAL, Mariano. (2005), Party System Institutionalization and Party System Theory: After the Third Wave of Democratization. Trabalho apresentado na Reunião Anual da American Political Science Association (APSA). Washington, DC, 1-4 de setembro.

MAUCERI, Philip. (1995), "State Reform, Coalitions, and the Neoliberal Autogolpe in Peru". Latin American Research Review, vol. 30, no 1, pp. 7-37.

MAUSER, Gary A. e FITZSIMMONS, Craig. (1991), “The Short-Term Effect of Election Polls on Foreign Exchange Rates: The 1988 Canadian Federal Election". The Public Opinion Quarterly, vol. 55, no 2, pp. 232-240.

MOSLEY, Lana. (2003), Global Capital and National Governments. Cambridge, Cambridge University Press.

MURILLO, María Victoria, OLIVEROS, Virginia e VAISHNAV, Milan. (2011), “Economic Constraints and Presidential Agency", in S. Levitsky e K. M. Roberts (eds.), The Resurgence of the Latin American Left. Baltimore, Johns Hopkins University Press, pp. 93-116.

OATLEY, Thomas. (1999), "How Constraining is Capital Mobility? The Partisan Hypothesis in an Open Economy". American Journal of Political Science, vol. 43, no 4, pp. 1003-1027.

PACHANO, Simón. (2004),“El Territorio de los Partidos. Ecuador, 1979-2002”, in S. Pachano et al. (eds.), Partidos Políticos en la Región Andina: Entre la Crisis y el Cambio. Lima, Ágora Democrática/IDEA, pp. 71-91.

PASTOR, Manuel e WISE, Carol. (1997), “State Policy, Distribution and Neoliberal Reform in Mexico". Journal of Latin American Studies, vol. 29, no 2, pp. 419-456.

PAYNE, J. Mark et al. (2002), Democracies in Development: Politics and Reform in Latin America. Washington, D.C., Inter-American Development Bank/The International Institute for Democracy and Electoral Assistance.

ROBERTS, Kenneth. (1996), "Economic Crisis and the Demise of the Legal Left in Peru". Comparative Politics, vol. 29, no 1, pp. 69-92.

ROBINSON, William I. (2000), "Neoliberalism, the Global Elite, and the Guatemalan Transition: A Critical Macrosocial Analysis". Journal of Interamerican Studies and World Affairs, vol. 42, no 4, pp. 89-107.

SANTISO, Javier. (2005), The Political Economy of Emerging Markets. New York, Palgrave MacMillan. 
e MARTÍNEZ, Juan. (2003), "Financial Markets and Politics: The Confidence Game in Latin American Emerging Markets". International Political Science Review, vol. 24, no 3, pp. 363-395.

STOKES, Susan. (2001), Mandates and Democracy: Neoliberalism by Surprise in Latin America. Cambridge, Cambridge University Press.

TOMMASI, Mariano. (2003), "Crises, Institutions Politiques et Réformes Politiques: Le Bon, le Mauvais et l'Affreux". Revue d'Économie du Développement, vol. 11, no 2, pp. 49-81.

VUCHELEN, Jef. (2003), "Electoral Systems and the Effect of Political Events on the Stock Market: The Belgian Case". Economics and Politics, vol. 15, no 1, pp. 85-102.

WEISS, Wendy. (1997), “Debt and Devaluation: The Burden on Ecuador's Popular Class". Latin American Perspectives, vol. 24, no 4, pp. 9-33.

WEYLAND, Kurt. (1996), "Risk Taking in Latin American Economic Restructuring: Lessons from Prospect Theory". International Studies Quarterly, vol. 40, no 2, pp. 185-208.

(2004), "Critical Debates Neoliberalism and Democracy in Latin America: A Mixed Record". Latin American Politics and Society, vol. 46, no 1, pp. 135-157.

. (2009), "The Rise of Latin America's Two Lefts: Insights from Rentier State Theory". Comparative Politics, vol. 41, no 2, pp. 145-164.

, MADRID, Raúl L. e HUNTER, Wendy. (2010), Leftist Governments in Latin America: Successes and Shortcomings. New York, Cambridge University Press.

WIBBELS, Erik e ARCE, Moises. (2003), "Globalization, Taxation, and Burden-Shifting in Latin America". International Organization, vol. 57, no 1, pp. 111-136.

WILSON, Bruce M. (1994), “When Social Democrats Choose Neoliberal Economic Policies: The Case of Costa Rica". Comparative Politics, vol. 26, no 2, pp. 149-168.

YANTEK, Thom e COWART, Andrew T. (1986), “Elections and Wall Street: Taking Stock of Parties and Presidents". The Western Political Quarterly, vol. 39, no 3, pp. 390-412.

ZECHMEISTER, Elizabeth J. e LUNA, Juan P. (2005), "Political Representation in Latin America: A Study of Elite-Mass Congruence in Nine Countries". Comparative Political Studies, vol. 38, no 4, pp. 388-416.

ZUCCO JR., Cesar. (2008), Stability without Roots: Party System Institutionalization in Brazil. Trabalho apresentado na conferência Institucionalización de los Sistemas de Partidos en América Latina. Barcelona, CIDOB, 20-21 de novembro. 


\section{Daniela Campello}

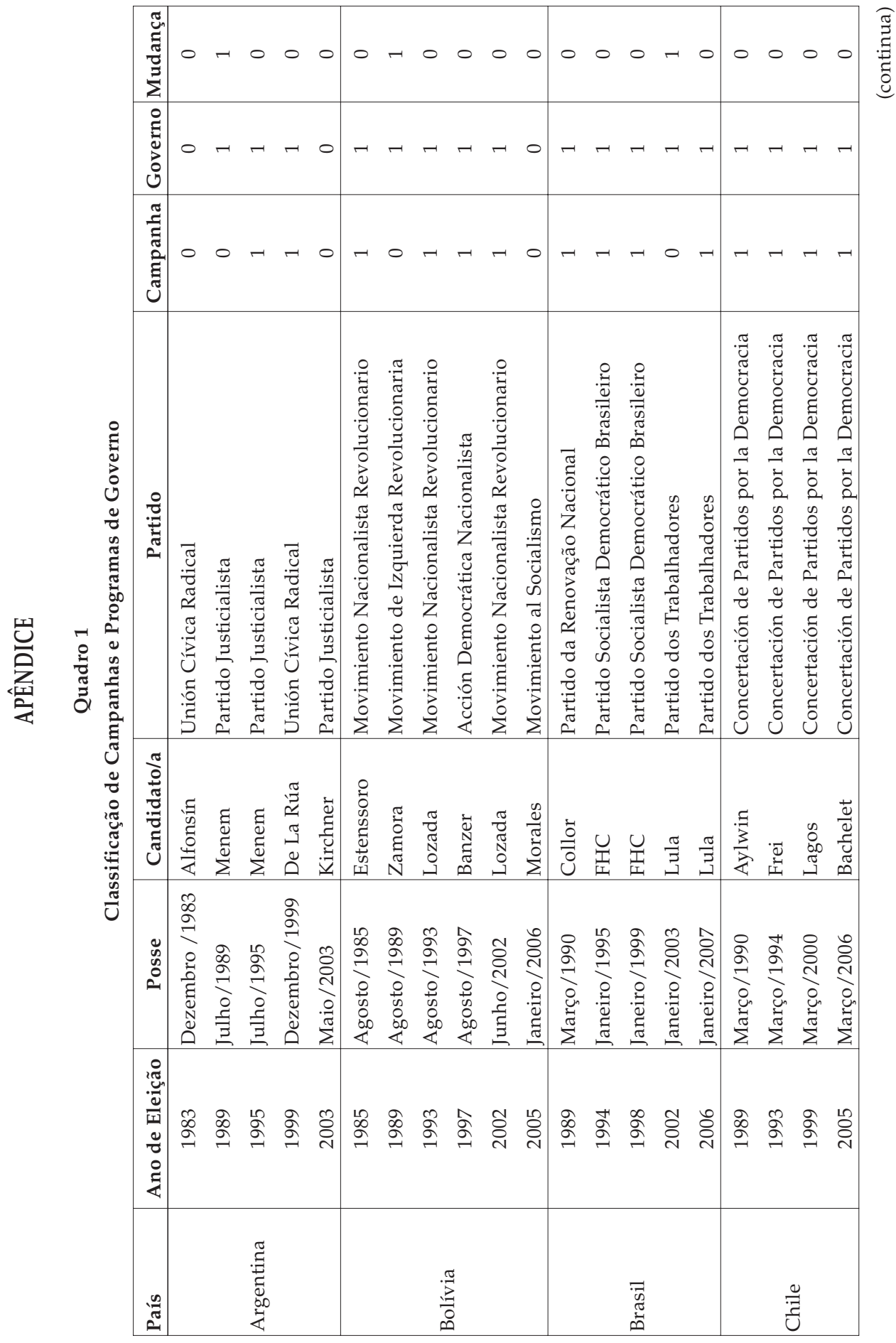

454 DADOS - Revista de Ciências Sociais, Rio de Janeiro, vol. 58, no 2, 2015 
Institucionalização Partidária e Consistência Programática...

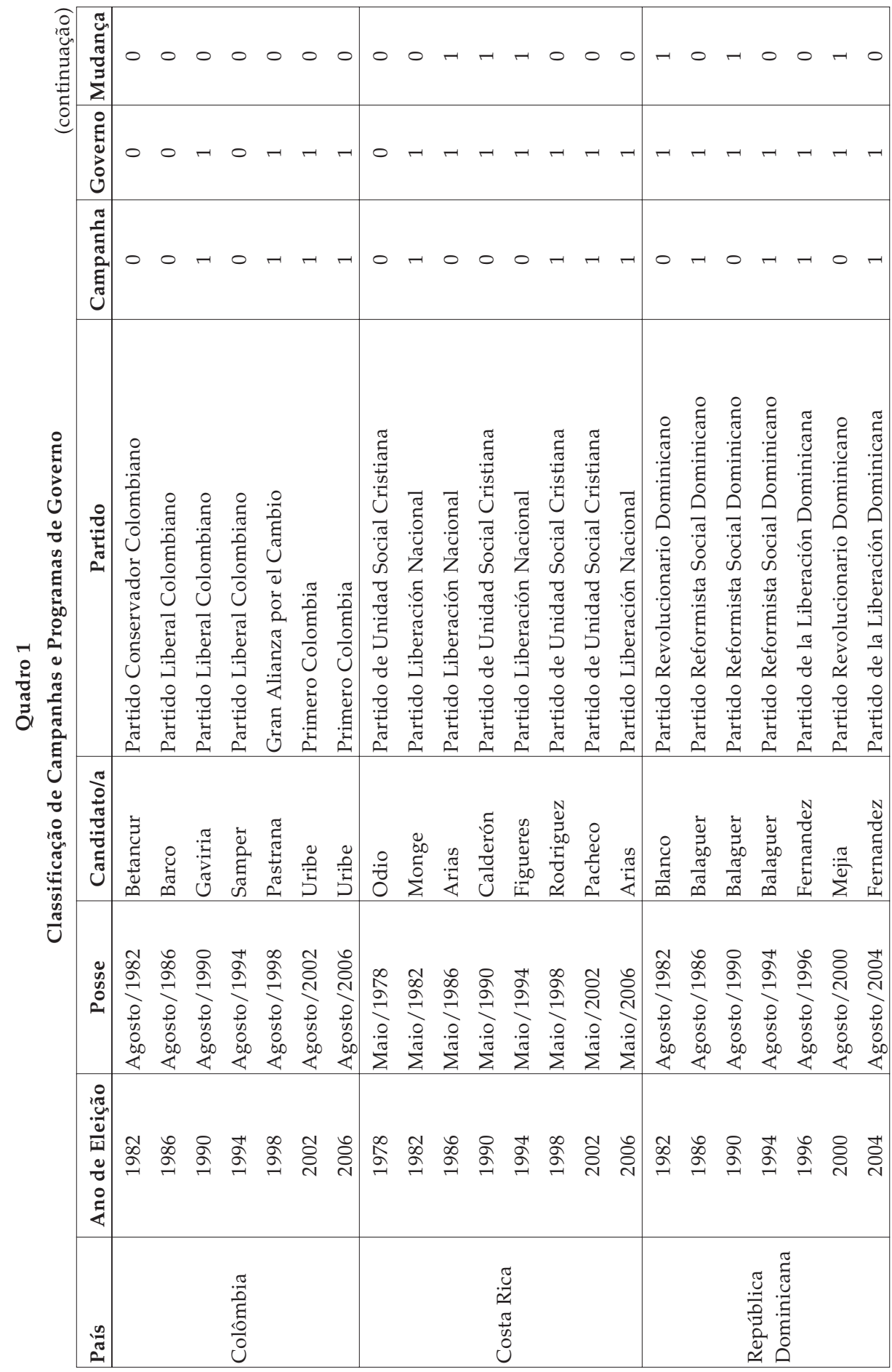

DADOS - Revista de Ciências Sociais, Rio de Janeiro, vol. 58, nํ2, 2015 


\section{Daniela Campello}

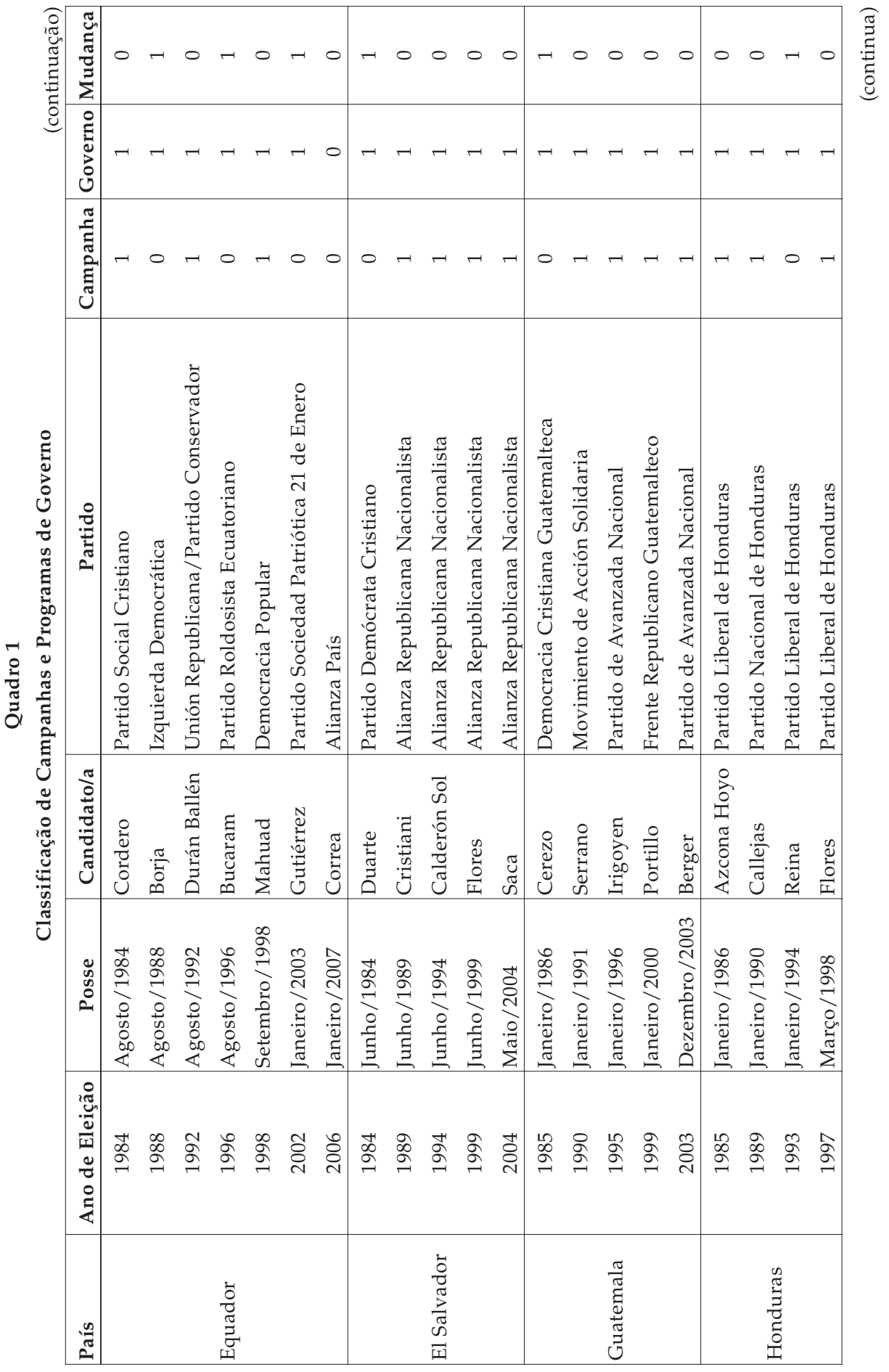

456 DADOS - Revista de Ciências Sociais, Rio de Janeiro, vol. 58, no 2, 2015 
Institucionalização Partidária e Consistência Programática...

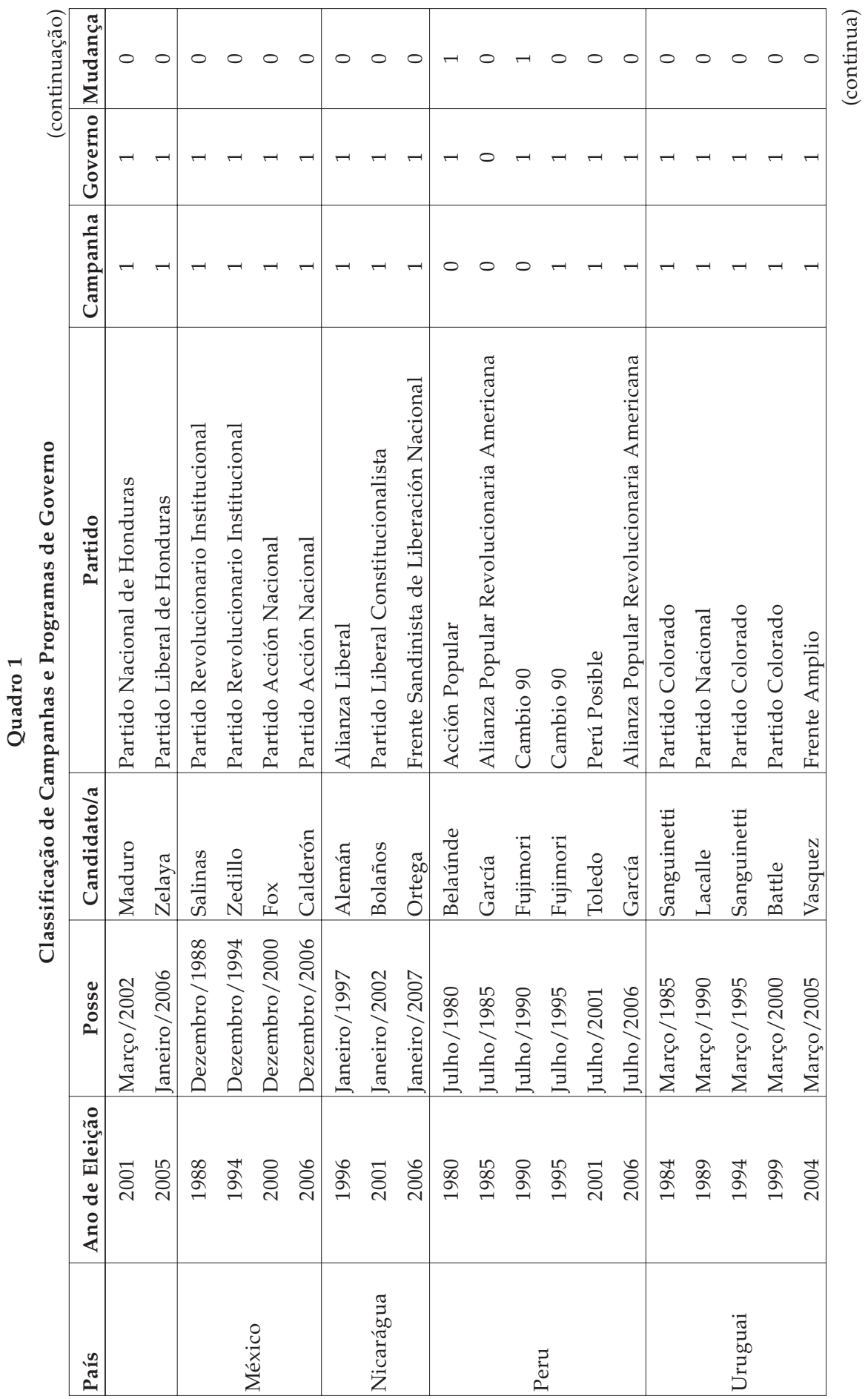

DADOS - Revista de Ciências Sociais, Rio de Janeiro, vol. 58, nํㅡㄹ 2015 


\section{Daniela Campello}

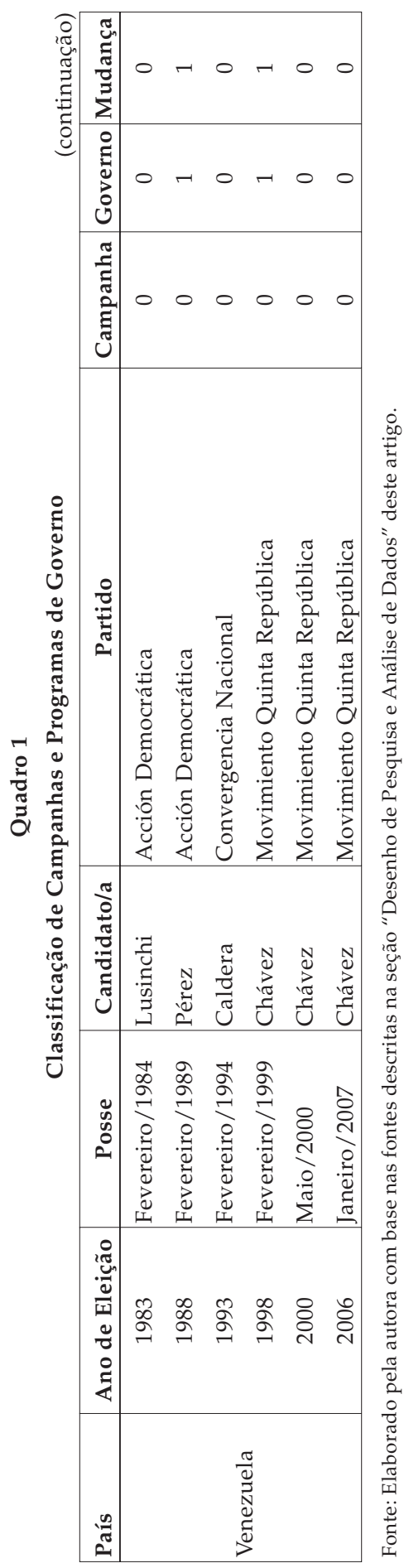

458 DADOS - Revista de Ciências Sociais, Rio de Janeiro, vol. 58, no 2, 2015 


\section{RESUMO}

Institucionalização Partidária e Consistência Programática: A Resposta da Esquerda a Ataques Especulativos na América Latina

Embora um importante esforço venha sendo empreendido com o intuito de estabelecer a institucionalização de sistemas partidários como uma dimensão crítica, as implicações políticas concretas dessa institucionalização têm recebido relativamente pouca atenção da academia. Pouco se sabe, por exemplo, sobre as formas através das quais ela promove a consistência programática de governos. Este artigo contribui para este debate investigando um fenômeno característico da política latino-americana - mudanças programáticas empreendidas por presidentes de esquerda empossados em meio a ataques especulativos - e examinando de que forma níveis de institucionalização afetam a probabilidade de que essas mudanças ocorram. Os resultados mostram que, deparados com fortes pressões especulativas, presidentes de esquerda tendem a abandonar suas promessas de campanha em favor de uma agenda econômica conservadora. Ao contrário do esperado, no entanto, essas mudanças ocorrem mais frequentemente em sistemas partidários institucionalizados.

Palavras-chave: ataques especulativos; neoliberalismo; mercado financeiro; esquerda; institucionalização

\section{ABSTRACT}

Party Institutionalization and Agenda Consistency: The Left's Response to Financial Speculation Attacks in Latin America

Although significant effort has been devoted to establishing the institutionalization as a critical dimension of parties and party systems, empirical analyses of the political implications of this institutionalization have received relatively little scholarly attention. Little is known, for example, about how it promotes governments' programmatic consistency. This article contributes to this debate by investigating a common trait of Latin American politics - programmatic shifts endeavored by left-wing governments who take office in the midst of speculative attacks - and examining how different levels of institutionalization affect the probability of such changes occurring. Results show that, confronted by strong speculative pressure, left-wing presidents tend to abandon their campaign promises in favor of conservative economic agendas. Contrary to expected, however, these changes occur more frequently in institutionalized party systems.

Keywords: speculative attacks; neoliberalism; financial market; left; institutionalization 


\section{Daniela Campello}

\section{RÉSUMÉ}

Institutionnalisation Partisane et Consistance Programmatique: La Réponse de la Gauche aux Attaques Spéculatives en Amérique Latine

Bien qu'un effort important soit en cours dans le but de prendre en compte l'institutionnalisation de systèmes partisans sous un angle critique, les implications politiques concrètes de cette institutionnalisation n'ont été que relativement peu étudiées par le monde universitaire. On ne sait par exemple que peu de choses sur les différentes manières dont elle promeut la consistance programmatique des gouvernements. Cet article veut contribuer à ce débat en analysant un phénomène caractéristique de la politique latino-américaine, à savoir les modifications programmatiques entreprises par des présidents de gauche prenant leurs fonctions au milieu d'attaques spéculatives, et en examinant de quelle façon les niveaux d'institutionnalisation affectent la probabilité de survenance de ces changements. Les résultats nous montrent que les présidents de gauche confrontés à de fortes pressions spéculatives tendent à abandonner leurs promesses de campagne au profit d'un programme économique conservateur. Mais contrairement à nos attentes, ces changements surviennent plus fréquemment au sein de systèmes partisans institutionnalisés.

Mots-clés: attaques spéculatives; néolibéralisme; marché financier; gauche; institutionnalisation

\section{RESUMEN}

Institucionalización Partidaria y Consistencia Programática: La Respuesta de la Izquierda a Ataques Especulativos en América Latina

Aunque un importante esfuerzo haya sido emprendido con el objetivo de establecer la institucionalización de sistemas partidarios como una dimensión crítica, las implicaciones políticas concretas de esta institucionalización han recibido menor atención por parte de la academia. Poco se sabe, por ejemplo, sobre las formas a través de las cuales ésta promueve la consistencia programática de los gobiernos. Este artículo se inserta precisamente en este debate, investigando un fenómeno característico de la política latinoamericana - cambios programáticos emprendidos por presidentes de izquierda investidos en medio a ataques especulativos - y examinando cómo niveles de institucionalización afectan la probabilidad de que estos cambios ocurran. Los resultados muestran que, frente a fuertes presiones especulativas, los presidentes de izquierda tienden a abandonar sus promesas de campaña a favor de una agenda económica conservadora. Sin embargo, al contrario de lo esperado, estos cambios ocurren con mayor frecuencia en sistemas partidarios institucionalizados.

Palabras clave: ataques especulativos; neoliberalismo; mercado financiero; izquierda; institucionalización 